and Ohio, rose to flood heights. The River Connecticut broke down dams and bridges, inundating towns and low-lying districts, and causing factories to close, throughout its entire length from northern New Hampshire to Long Island Sound. In the State of Massachusetts, industry and transport were similarly paralysed. The damage to property in New England is put at more than ten million sterling. Farther south, the River Potomac has been badly swollen and the city of Washington was invaded. Although at the time of going to press the floods are reported to be subsiding in the afflicted districts, apprehensions are entertained as to the creation of new danger areas when the augmented waters of the Ohio reach the Mississippi at Cairo (Illinois). Portsmouth (Ohio) and Cincinnati are threatened, and hurried precautionary measures are being taken. So widespread has been the calamitous visitation that it has extended even into Canada, affecting the provinces of Ontario, Quebec and New Brunswick. Fredericton, the capital of New Brunswick, has been largely under water, in addition to large stretches of the adjoining country.

\section{'Bush' Culture in the New Hebrides}

OWING to recent economic developments in the islands of the Pacific, it is becoming increasingly difficult for the anthropologist to find material for observation there in the field of social and cultural anthropology. The sophistication of the native through European contacts has indeed always been a difficulty, but post-War development, especially plantation employment, has led to a rapid disintegration and even a blurring of the memory of tribal institutions. Such, for example, was the experience of Miss Beatrice Blackwood in the Solomon Islands, when she was compelled to seek the remoter islands of the group before she could begin her investigations. A similar experience befell the members of the Oxford University expedition to the New Hebrides. It is noted in the recent report of the Oxford University Exploration Society that it was only in the bush that unspoiled material was to be found. Here, however, conditions are still to a considerable extent unchanged, as was indicated in the account of the natives of Malekula given before the Royal Geographical Society on March 16 by Mr. T. H. Harrison, who resided on this island of the New Hebrides from August 1934 until July 1935, and took a census of the inhabitants of this and the adjacent small islands. $\mathrm{He}$ assesses their numbers at approximately 10,000 .

THE Malekulans are not entirely unknown to European science. They were studied intensively by the young Cambridge anthropologist J. Deacon, whose recent untimely death when on his return will always be held a heavy loss to science. $\mathrm{Mr}$. Harrison, however, is of the opinion that the natives of Malekula, who have come under scientific observation through their European contacts, are free from the effects of certain psychological elements, which he observed as present among the inhabitants of the northern areas. Here man-hunting is both a sport and an ever-present cause of fear. War, arising out of inter-village vendettas, is perennial. The people of Amok, a large village of 1,000 inhabitants, are real 'man-bush' and are referred to as such by their neighbours. During the year Mr. Harrison was with the Big Nambas, thirty men were killed and about seven were successfully taken back and eaten. Among the bush people the effect of the impact of the white man has been practically nil. They are still primitive-minded and dangerous in the old New Hebridean way. Notwithstanding this, Mr. Harrison maintains that these peoples are in many ways the most admirable in the Pacific. They have all their old zest and vigour, the will to live and their dogmatic pride. Yet though their mind is unimpaired, civilisation is rotting them away through disease. In 1932 whooping cough carried off six hundred Big Nambas, and in 1934 influenza caused about one hundred deaths.

\section{Orthodox and Proselyte in Hinduism}

AN interesting sidelight on the interplay of religious and political cross-currents is afforded by the ceremonial admission to Hinduism of proselytes of both sexes and all ages to the number of one hundred and fifty, which took place in an initiation by the Pandit Madan Mohan Malaviya on March 17 at Bombay. This was in part a demonstration against the attitude of the more rigidly orthodox Hindus, and in part a phase of the widespread movement, of long standing, but now of increasing civil importance, of adding to the nominal roll of Hinduism. This policy, which may fairly be regarded as liberal, is at present to some considerable extent influenced by the threat. ened danger that the Untouchables, irked by their ritual disabilities and the intolerance of the orthodox, may withdraw entirely from Hinduism, with serious political repercussions. An interesting account of the initiation by the venerable septuagenarian Pandit is given by the Bombay correspondent of The Times in the issue of March 18. It consisted of a purification ceremony, in which, to the recitation of sacred texts, the converts, with foreheads adorned with the holy red powder, bathed in the river and then bowed before the Pandit Malaviya, who sat under the holy peepal tree. $\mathrm{He}$ then gave to each a portion of Panchgarya, the sacred compound of the five products of the cow-milk, curd, ghee, urine and dung. When this had been consumed the Pandit whispered in the ear of each the Nama Shivaya, which is supposed to open heaven's gateway, and each convert vowed to speak the truth, to observe cleanliness, and to abstain from beef and liquor. To each was then given a petal of the sacred tulsi plant, a rosary card with rules of conduct and a piece of cloth on which were printed incantations. It is hoped by the reformers, it is stated, that these neo-Hindus will be accepted as full members of the community by the orthodox within ten years.

\section{Tobacco Disease in Australia}

THE tobacco-growing industry in Australia has in recent years suffered heavy losses from the disease commonly known as 'downy mildew' or 'blue-mould' (Peronospora tabacina). To raise disease-free seedlings in the principal growing areas by customary methods 
has become almost impossible. Importation of plants from New Zealand has been attempted, but without marked success; and efforts have been made to establish seed-beds at Hermansburg Mission Station in Central Australia, where possibly infestation may not occur. Happily a means of overcoming the difficulty appears to have been demonstrated by $\mathrm{Dr}$. H. R. Angell, of the Council for Scientific and Industrial Research. His method is to allow benzol (or certain other hydrocarbon mixtures) to evaporate in the seed-beds during the night time and on dull days when the beds are under cover. While neighbouring untreated control beds may be completely destroyed, those subjected to the vapour remain healthy; in fact, no development follows even from artificial inoculation. During the present season extensive trials have been made in New South Wales, Victoria, South Australia and Western Australia with uniformly successful results. It is true that there remains a risk of infection when the seedlings are planted out, but this is relatively slight compared with the danger in the seed-beds; and it would appear that an economical, practical and effective means of destroying what is perhaps the greatest obstacle in the way of stabilising the tobacco industry in Australia has been developed and proved.

\section{Importance of Small Coal}

WHEN Dr. F. S. Sinnatt addressed the Institution of Civil Engineers on "Some Major Problems in the Utilisation of Coal" on March 17, he gave first place to the choice of coal suitable in composition, properties and preparation for the purpose in view, and emphasised the importance of collecting such information. Quoting examples from the work of the Coal Survey, he showed the great diversity of properties, even in one seam, and over comparatively small distances. Until these variations are exactly established, progress in rational marketing will be hampered. The needs of the consumer change. Large coal is in less demand, and is to an increasing extent being actually broken. The technique of mining, which has been designed to conserve lump coal, may be radically altered in favour of machine mining, which is prone to produce more fine coal. The breakage of coal is becoming of paramount importance to the coal industry, and involves many problems still requiring solution, and these are chemical, physical and particularly engineering. The disposal of fine coal dust involves consideration of the combustion of pulverised fuel, which steadily extends, hitherto mainly.in large units. For small units, coal can now be obtained ready pulverised, and the Fuel Research Station has developed a new burner with which it can be burnt with a short flame. The use of pulverised fuel in Lancashire boilers thus becomes practicable, with advantage to the performance. Apparently output of steam may be doubled without loss of efficiency. The development of firing with pulverised fuel in small units will call for means for retaining the emission of grit and sulphur, and although this has been solved so far as large power stations are concerned, there is still scope for plant suitable for smaller units.

\section{Atmospheric Pollution}

THE twenty-first report of the Investigation of Atmospheric Pollution issued by the Department of Scientific and Industrial Research (H.M. Stationery Office. 5s.) may be summarised in one sentence: "The general cleanness of our atmosphere is not improving" - a statement opposed to an impression widely held. The observations recorded in London seem particularly to point this way, and to show that while Metropolitan conditions get worse, provincial conditions improve. Some of the worst figures are recorded at London stations, compared with which the industrial areas in the provinces appear relatively good. This must be disquieting to residents of the Metropolis, and emphasises the need for more energy to promote the consumption of fuel by methods which minimise the emission of tar, soot and sulphur acids. Some of the anomalies suggest the need for caution in interpretation. After all, the figures relate only to the sites where examples are taken, and these are relatively few, and a statistical analysis by Mr. B. H. Wilsdon shows that other factors such as rainfall influence the results. The report deals with observations made for the year ending March 1, 1935, and it may be that increased industrial activity has involved an increased consumption of fuel which has compensated for some improvement in method of combustion.

\section{Cine-Radiography}

RöntGen announced his discovery of X-rays late in 1895. A few years afterwards, attempts were made to get cinematograph records of the pictures obtained by them; but they were crude. It was found that a speed from a $\frac{1}{2}$ to 1 second is perfectly effective for a good many movements. In a paper read to the Institution of Electrical Engineers on March 19, Mr. Russell J. Reynolds gave the latest developments in cine-radiography. There are two methods in general use. In the direct method, a band of film is placed in the position normally occupied by the fluorescent screen. This has the disadvantage that the dimensions of each exposure must be at least 4 in. $\times 5$ in. A film of this size is very costly, and an apparatus capable of moving it at the rate of 8 or more ex. posures per second is cumbersome and difficult to design. In the indirect method, the image on the fluorescent screen is photographed with an ordinary cinematograph apparatus. The chief difficulty in obtaining a sufficiently brilliant image on the screen lies in the fact that the film is minute and moves at a high speed. The heavy currents necessary wear out the tubes quickly, and it is dangerous to expose the patient to intense radiation for the time necessary to take the film. It has to be remembered also that the effect of the rays is cumulative. Mr. Reynolds gives full particulars of the apparatus he has evolved to overcome the difficulties of the indirect method. It gives a sufficiently brilliant screen picture to impress itself satisfactorily on the film when exposed for only a small fraction of a second. The film is protected from exposure to the rays, and the exposure of the patient to the rays is harmless. By this ap. paratus the radiologist obtains a rapid, inexpensive 